\title{
Historical recidivism rates of Alberta's not criminally responsible population
}

\author{
Kayla Richer,* Jeremy Cheng, ${ }^{\dagger}$ Andrew M. Haag* ${ }^{\star} \S$
}

\begin{abstract}
In Canada, public safety is a paramount concern for the provincial Review Boards that oversee individuals found to be Not Criminally Responsible on Account of Mental Disorder (NCR). There is limited research on recidivism rates for NCR populations to assist public policy and institutional practices. In response to this gap, the authors examined the recidivism characteristics of the population of NCR individuals who have passed under the Review Board of Alberta, Canada. The maximum follow-up period was 35 years and included 528 cases between October 1941 and December 2015. Results indicated that the overall general recidivism rate of NCR individuals was 19.7\% (convictions). Of this percentage, $4.6 \%$ received a major violent conviction, $12.6 \%$ received a violent conviction, and $0.75 \%$ received a sexual conviction. The presence of a mood or psychotic disorder resulted in a slightly lower likelihood for recidivism, whereas longer criminal histories led to a greater likelihood of recidivism. The findings are discussed for their implications on forensic practice.
\end{abstract}

Key Words The Alberta NCR project; not criminally responsible; recidivism; forensic mental health; mental disorder; violence; NCR.

Journal of CSWB. 2018 Oct;3(2):59-64

www.journalcswb.ca

\section{INTRODUCTION}

In Canada, persons who are found to have a mental illness at the time of their criminal offense that (1) rendered them unable to appreciate the nature of their criminal act or (2) rendered them incapable of knowing that there criminal offence was wrong are said to be Not Criminally Responsible on Account of a Mental Disorder (NCR). Under section 672.54 of the Canadian Criminal Code, there are three dispositions available to a court or Review Board for persons found to be NCR: (1) a full warrant or detention in hospital, (2) a conditional discharge, or (3) absolute discharge. A full warrant refers to the detention of an individual with no or limited community access. In the event of a conditional discharge, the person found to be NCR would be supervised in the community with restrictions imposed on their liberty. In the case of an absolute discharge, the NCR person would no longer be under the jurisdiction of a provincial review board and would return to being a member of the community.

In order to better understand the context of Review Board decision making, it is thought that one should understand the demographics of those who have been found to be NCR (Haag, Cheng, \& Wirove, 2016), in addition to the public policy/legal statutes. Sequentially, it is equally as important to consider an additional characteristic of this population: recidivism.

The literature provides either outdated or incomplete provincial data on Canadian NCR recidivism rates (Charette,
Crocker, Seto et al., 2015; Luettgen, Chrapko, \& Reddon, 1998). For instance, Luettgen et al. (1998) researched the increase in community-based treatment of individuals found NCR and their rates of recidivism. The researchers noted that the principle of least restrictive care has historically encouraged the integration of NCR individuals into society. Luettgen et al. (1998) summarized the NCR recidivism rates from previous studies, which have ranged "from 5.4\% in Ontario to $65.8 \%$ in Maryland" (p. 89). The wide range in the rates of recidivism was explained due to the fact that "it is difficult to generalize between studies and populations" (p. 90).

Conducted at Alberta Hospital Edmonton, Luettgen et al. (1998) studied 109 NCR patients, all of whom had received treatment for 30 days or more in the hospital's Forensic Service. Follow-up data on these patients were gathered from the Alberta Hospital Edmonton's databases, along with several other sources. Of the cohort, $69.7 \%$ were re-integrated into the community, where half lived in group homes and the other half resided in their own homes. Results indicated that eight integrated patients had reoffended in the community, and of these eight, only two had committed violent crimes when they reoffended. These results contradicted the misconception that NCR individuals are prone to recidivism (Crocker, Nicholls, Seto et al., 2015a) and should not be granted the right to be integrated back into society.

More recently, Charette et al. (2015) studied recidivism in their analysis of NCR individuals within British 
Columbia, Ontario, and Quebec. In their study examining those found NCR between the year 2000 and 2005, they discovered a relatively low recidivism rate of $23.5 \%$ during the five-year follow-up period. The researchers realized that individuals who had severe, violent index offences were much less likely to reoffend ( $6 \%$ after three-year follow-up) as compared to those who had committed less severe index offences (15.3\% after three-year follow-up). In addition, past criminal convictions, NCR findings, and psychiatric diagnosis were good predictors of future offending. Lastly, Charette et al. (2015) described the significance of review boards in that recidivism rates were lower in those individuals who were involved with review boards. The researchers stressed that recidivism among persons found NCR was a rarity, particularly when compared to offenders who do not have a mental disorder.

A meta-analysis by Bonta, Law, and Hanson (1998) found that a variety of factors were associated with general and violent recidivism including criminal history, psychiatric diagnosis, and severity of the index offense. In addition, those found NCR were less likely to reoffend than those without this verdict. Coinciding with the findings by Charette et al. (2015), Bonta et al. (1998) found that those with mental illnesses who committed serious offenses (i.e., homicide, sexual offenses) were less likely to reoffend than those who committed less serious offenses (i.e., property damage, possession).

As with other areas in the criminal justice system, there will always be a need for systematic, quality data to be collected on the issue of criminal recidivism. Certainly, the subpopulation of those found NCR is no exception to this. Ideally such data should be collected at the population level to avoid problems with collecting representative samples (Szklo, 1998). The advantage of population level data is that greater accuracy can be achieved with "demographic, epidemiological, and clinical characteristics of the prevalent target population" (Ethgen \& Standaert, 2012, p. 171). To date, the best Canadian NCR studies have considered rates of recidivism of cohorts as opposed to population (e.g., Crocker et al., 2015a)_an approach with advantages to finding appropriate samples. It is acknowledged that for many reasons, population-level research may not always be feasible.

Although there are data on Canadian NCR recidivism rates, several provinces and territories are understudied, including Alberta. The current study sought to build upon the Alberta NCR Project (Haag et al., 2016) and report the recidivism rates for the population of NCR individuals in Alberta's history. It was a secondary aim to determine the impact of psychiatric diagnosis, severity of crime, and criminal history on recidivism for the Alberta NCR population. Data were collected from Canadian Police Information Centre (CPIC) criminal records and archived patient charts. CPIC records were coded for convictions post-NCR verdict, and archived patient charts were coded for the time of earliest unsupervised privilege. Given the past research on Canadian NCR groups, it was expected that recidivism rates would be relatively low, especially when compared to general offender populations. Furthermore, predictors of recidivism for NCR accused should also be similar to those that apply to general offenders.

\section{METHODS}

Design

This study is an expansion of the Alberta NCR Project, a retrospective longitudinal program of research on NCR individuals throughout Alberta's history. The current research also used a retrospective longitudinal design to track recidivism data on the population of NCR individuals who have been placed under the jurisdiction of the Alberta Review Board (ARB). The minimum follow-up period was 1 year, with a maximum of 35 years.

\section{Procedure}

Recidivism data were processed by the authors and counted only convictions post-NCR verdict. Although there is debate on the merits of charges versus convictions for recidivism estimates, some research suggests that there are no significant differences on the use of either operation on final results (Harris, Rice, Quinsey et al., 2015). Thus, the authors opted for a conservative outlook on recidivism rates via convictions. Recidivism follow-up periods began at the time of the earliest unsupervised privilege or, if a conviction occurred prior to the first unsupervised privilege, post-NCR verdict. Typically, unsupervised privileges would be the first opportunity for recidivism after hospitalization (full warrant) for those found to be NCR. Recidivism data were subject to two units of analysis, crude and adjusted. Crude analysis included all cases prior to inclusion criteria and did not account for death and deportation. Adjusted analysis included the cases left after inclusion and exclusion criteria. Smaller samples sizes, as follow-up periods advanced, were a result of cases being removed due to exclusion criteria.

\section{Inclusion Criteria}

Inclusion criteria involved cases that reoffended in the followup period, and those who went Absent Without Official Leave (AWOL). In the event of death, cases counted up until the last completed follow-up period. In the event of deportation, cases counted only towards the follow-up period completed in Canada.

\section{Exclusion Criteria}

Exclusion criteria involved cases that became NCR after recidivism data were collected, died prior to any supervised release, never been given an unsupervised release and never reoffended, and persons transferred out of province prior to unsupervised privilege being granted (there was no way to determine when out of province unsupervised privileges started). In the event of a known death or deportation after release, cases were included until the known date of the event and then no longer included.

\section{Sources of Data}

Data were sourced from CPIC records and patient files. CPIC records were collected from the Royal Canadian Mounted Police in December of 2015 and coded for the date and type of conviction across four categories: sexual, major violent, violent, and general. Sexual offenses involved any crime of a sexual nature (i.e., sexual assault, sexual harassment, sexual indecency). Major violent offenses included assault causing bodily harm, aggravated assault, assault with a weapon, 
homicide, and attempted homicide. Violent offenses included sexual violence and robbery. General offenses included a conviction for any crime. Data were checked at least twice by two independent coders, with group consultation available for discrepancy behind criminal record interpretations. As for NCR patient files, the authors reviewed and coded for the earliest date of unsupervised privilege and the type of privilege allocated (e.g., unsupervised grounds, unsupervised city passes).

\section{Participants}

A total of 528 cases were included in this study between October 1941 and December 2015. The gender composition was 84 per cent male and 16 per cent female with an average age of 35.3 years at the time of NCR verdict. Table 1 displays the psychiatric diagnoses at the time of NCR verdict. Table 2 shows the distribution of index offense types at the time of NCR verdict. Cumulative percentages for the tables exceeded 100 per cent due to multiple index offenses or diagnoses in some cases. For a further breakdown of sociodemographic, mental health, and criminological profiles see Haag et al. (2016).

\section{Analytic Strategy}

Descriptive data on recidivism rates were analyzed with frequency statistics. Multiple regression was conducted to examine predictors of recidivism. Predictors entered in the regression included diagnosis (i.e., mood disorder, psychotic disorder, and substance use disorder), and criminological traits (i.e., criminal history, index offense severity). The data for this project were compiled, processed, and reported

TABLE I Psychiatric diagnoses for Alberta's NCR population

\begin{tabular}{lc}
\hline & $\mathbf{n}(\%)$ \\
\hline Psychotic Disorder & $385(74.2)$ \\
Mood Disorder & $154(29.7)$ \\
Substance Abuse Disorder & $192(37)$ \\
\hline
\end{tabular}

TABLE II Distribution of index offences for Alberta's NCR population

\begin{tabular}{lc}
\hline \multicolumn{1}{c}{ Type of Offence } & $\mathbf{n}(\%)$ \\
\hline $\begin{array}{l}\text { Direct Violence (excluding sexual offences, homicide, } \\
\text { and attempted homicide) }\end{array}$ & $256(46.9)$ \\
Homicide & $101(18.5)$ \\
Weapons & $91(16.6)$ \\
\hline Attempted Homicide & $58(10.6)$ \\
Arson & $36(6.6)$ \\
Sexual Offences & $34(6.2)$ \\
Robbery & $32(5.9)$ \\
Criminal Harassment & $17(3.1)$ \\
Offences directly related to intoxicants & $4(.7)$ \\
Drug possession/trafficking & $2(.4)$ \\
Counsel To Commit Murder & $1(.2)$ \\
Conspiracy To Commit Murder & $1(.2)$ \\
All Other Offences & $179(32.7)$ \\
\hline
\end{tabular}

using the Statistical Package for the Social Sciences (SPSS) (IBM Corp, 2010).

Ethics

Ethics approval for this research was acquired from both Alberta Health Services and the Research Ethics Office at the University of Alberta.

\section{RESULTS}

For crude recidivism analysis, 14 cases were removed after exclusion criteria, leaving a remainder of 528 cases. For adjusted recidivism, there were 528 cases after two years, 485 cases after five years, and 477 cases after ten years and beyond. Table 3 displays the crude and adjusted recidivism rates across major violent, violent, and general recidivism. It should be noted that sexual recidivism was not included due to exceedingly low rates of sexual recidivism. Figure 1 illustrates the survival curve for crude and adjusted recidivism rates except for sexual recidivism. There were four cases of sexual recidivism out of 528 potential. There was one sexual recidivist within four years, one additional case within seven years, and two additional cases within 14 years. In the history of Alberta, 19.7\% ( $=87$; adjusted rates) of those found NCR reoffended after 35 years of follow-up. Across recidivism categories after 30 years, adjusted recidivism

TABLE III Recidivism rates by offense type

\begin{tabular}{|c|c|c|}
\hline & $\begin{array}{c}\text { Crude } \\
\text { Recidivism (\%) }\end{array}$ & $\begin{array}{c}\text { Adjusted } \\
\text { Recidivism (\%) }\end{array}$ \\
\hline \multicolumn{3}{|c|}{ Major Violent Recidivism } \\
\hline 2 Year Rate & 0.8 & 0.8 \\
\hline 5 Year Rate & 1.7 & 1.9 \\
\hline 10 Year Rate & 2.8 & 3.1 \\
\hline 15 Year Rate & 3.8 & 4.2 \\
\hline 20 Year Rate & 4 & 4.4 \\
\hline 25 Year Rate & 4 & 4.4 \\
\hline 30 Year Rate & 4.2 & 4.6 \\
\hline \multicolumn{3}{|l|}{ Violent Recidivism } \\
\hline 5 Year Rate & 1.9 & 1.9 \\
\hline 10 Year Rate & 4.7 & 5.2 \\
\hline 15 Year Rate & 8 & 8.8 \\
\hline 20 Year Rate & 10.4 & 11.5 \\
\hline 25 Year Rate & 11 & 12.2 \\
\hline 30 Year Rate & 11 & 12.2 \\
\hline 35 Year Rate & 11.4 & 12.6 \\
\hline \multicolumn{3}{|c|}{ General Recidivism } \\
\hline 5 Year Rate & 4.5 & 4.5 \\
\hline 10 Year Rate & 9.3 & 10.1 \\
\hline 15 Year Rate & 13.8 & 15.3 \\
\hline 20 Year Rate & 17 & 18.9 \\
\hline 25 Year Rate & 17.4 & 19.3 \\
\hline 30 Year Rate & 17.6 & 19.5 \\
\hline
\end{tabular}



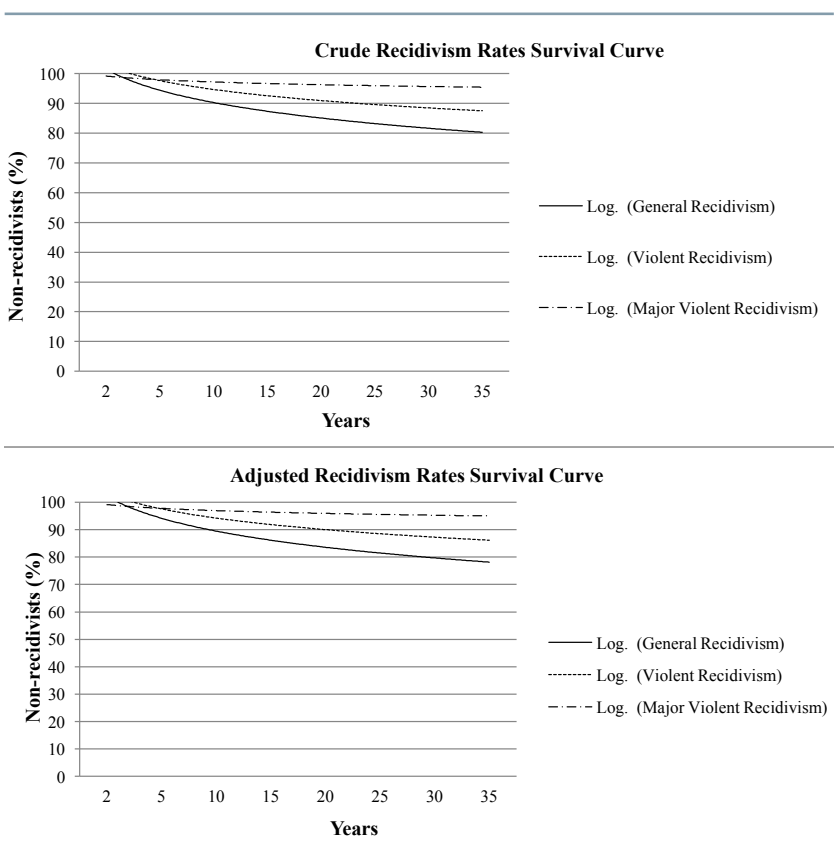

FIGURE 1 Survival curve for crude and adjusted recidivism rates by type of recidivism (excluded sexual recidivism).

rates from lowest to highest were sexual violence $(\mathrm{N}=4$; $0.75 \%)$, major violent recidivism $(\mathrm{N}=22 ; 4.6 \%)$, and violent recidivism $(\mathrm{N}=59 ; 12.2 \%)$. General and violent recidivism risk stabilized after 20 years, whereas major recidivism stabilized after 10 years. It was notable that there have only been four female NCR recidivists throughout Alberta's history; only one of whom committed an act of major violent recidivism.

Analyzing recidivism rates by disposition, when recidivism occurred, $32.2 \%$ of the time $(\mathrm{N}=28)$ was during a full warrant, $11.5 \%(\mathrm{~N}=10)$ during a conditional discharge, and $56.3 \%(\mathrm{~N}=49)$ after an absolute discharge.

For mental health and criminological analyses, nine cases were removed due to missing data for a total of 519 cases. Cohen's (1988) guidelines suggest $f^{2} \geq 0.02, f^{2} \geq 0.15$, and $f^{2} \geq 0.35$ represent small, medium, and large effect sizes, respectively. There was a significant negative, but small, main effect of mood disorder whereby its presence resulted in a .076 per cent decrease in recidivism, $t(513)=-2.066, p=.039$, $f^{2}=.091$. There was also a significant negative main effect of psychotic disorder whereby its presence related to a .141 per cent decrease in recidivism, $t(513)=-3.676, p<.001, f^{2}=.165$. There was not a significant relationship between a comorbid substance abuse disorder and recidivism, $t(513)=-.963, p=$ .336. The presence of a mood or psychotic disorder resulted in a lower likelihood of recidivism, with a psychotic disorder having a larger effect than a mood disorder.

The results indicated that there was a significant positive main effect for the number of previous sentences where, for every one additional conviction, there was a .015 per cent increase in recidivism rates, $t(513)=4.174, p<.001, f^{2}=.189$. Severity of index offense did not have a significant relationship with recidivism, $t(513)=.281, p=.779$. Overall, longer criminal histories led to a greater likelihood of recidivism, whereas the severity of the index offense did not.

\section{DISCUSSION}

The primary aim of this study was to report the recidivism rates for the NCR population throughout Alberta's history. In the study period, $19.7 \%$ of NCR individuals reoffended, with $12.6 \%$ of those reoffenses being violent. Lower recidivism rates were found for more severe crimes, namely sexual violence $(0.75 \%)$ and major violent recidivism $(4.6 \%)$. Furthermore, recidivism risk for severe crimes stabilized faster than less severe crimes (10 and 20 years, respectively). The findings of this study converge with previous research showing similarly low rates of general and violent recidivism among Canadian NCR samples (22\%; Charette et al., 2015) and international NCR samples (Marais \& Subramaney, 2015; Wang, Zhang, Jiang et al., 2007; Bonta et al., 1998). Furthermore, the results show that those NCR persons under the Alberta Review Board have lower general recidivism rates compared to other offender groups within Canada and internationally, as established by other research (Hanson \& Morton-Bourgon, 2005; Rice \& Harris, 1992; O'Donnell, Baumer, \& Hughes, 2008; Langan \& Levin, 2002; Baumer, Wright, Kristinsdottir et al., 2002). Given that Review Boards are typically responsible for the granting of dispositions/privileges which subsequently provide the legal framework for the supervision of the NCR population, it appears that these tribunals have successfully upheld public safety based on reconviction rates found in the current study.

The current results suggest the ARB has been successful in providing a framework for risk management when granting conditional discharge. These current results, however, diverge slightly from other studies with Canadian NCR groups/samples that reported patterns of recidivism rates from lowest to highest in relation from full warrant to absolute discharge (Charette et al., 2015). Although, the current study found that most reoffenses occurred after an absolute discharge, there were higher rates during a full warrant than a conditional discharge. There are several ways to explain this phenomenon. Given that the majority of recidivism occurs within five years post-release (Durose, Cooper, \& Snyder, 2014; James, 2015; Porporino, \& Motiuk, 1995), it is unsurprising that most reoffenses occurred after an absolute discharge. Individuals found to be NCR in Alberta spend an average of 5.7 years under the Review Board (Haag et al., 2016), the majority of it under a full warrant. Given the length of time of a full warrant and that the first unsupervised release almost always occurs in the context of a full warrant, it is not surprising that there is recidivism for some NCR accused prior to being granted a conditional discharge. Moreover, it should be noted that it is not uncommon for those found NCR in Alberta to be living in the community on an approved accommodation while still on a full warrant. Furthermore, one should consider that there are risk management plans developed for NCR individuals from the moment they become NCR in Alberta. By the time that an NCR accused is being considered for a conditional discharge, the treatment team and the ARB would likely have confidence that the idiosyncratic risk management plan has been adequate to manage risk and it is reasonable to progress the NCR accused to a less supervised state. In other words, a person who is on conditional discharge should have demonstrated that they are a manageable risk over time prior to being granted a conditional discharge. 
While on conditional discharge, there is still mandatory supervision and support for the NCR accused until they reach an absolute discharge. After an absolute discharge, any support received would be voluntary. Given the presence of supervision and managed risk, one would expect relatively low rates of recidivism while on conditional discharge. When one considers other empirical literature, in one study, general psychiatric populations were found to commit the majority of recidivism (44\%) during inpatient status at open psychiatric hospitals (Rice \& Harris, 1992), but otherwise have low recidivism rates post-release. In sum, the patterns of recidivism based on disposition type in the current study are consistent with past research.

It was a secondary aim of this research to determine the impact of mental health and criminological traits on recidivism rates for the Alberta NCR population. There was an inverse relationship between a severe mental disorder and recidivism in this study, a finding supported by other research on mentally disordered and general offenders (Bonta et al., 1998; Doyle, Logan, Ludlow et al., 2012; Douglas, Guy, \& Hart, 2009; Hall, Miraglia, Lee et al., 2012; Lund, Hofvander, Forsman et al., 2013; Ostermann \& Matejkowski, 2014; Nilsson, Wallinius, Gustavson et al., 2011; O'Driscoll, Larney, Indig et al., 2012). Although mental health care is an important aspect of general medical treatment, it should not be viewed in the context of risk as a poor contributor to recidivism. Contrary to other studies, we found that comorbid substance abuse did not hold a relationship with recidivism (Bonta et al., 1998; Charette et al., 2015). One reason for this finding may be that the low base rates of recidivism in our study, general $(19.7 \%)$ and violent $(12.6 \%)$, rendered a lack of power to detect an effect. Indeed, many studies support that comorbid substance abuse disorder is an additive risk factor for recidivism amongst mentally disordered and general offenders (i.e., Grann, Danesh, \& Fazel, 2008; Harris et al., 2015; Howard, McCarthy, Huband et al., 2013; Lund et al., 2012; Nilsson et al., 2011). Furthermore, given that intoxication at the time of a criminal act should greatly decrease the likelihood of being found NCR in the first place ( $\mathrm{R}$ v Bouchard-Lebrun, 2011; Criminal Code, 1985), there are fewer NCRs with substance use disorders relative to general offender populations.

As for criminological traits, the finding that criminal history was a good predictor of recidivism coincides with other research on mentally disordered offenders and offenders alike (Bonta, Blais, \& Wilson, 2014; Bonta et al., 1998; Charette et al., 2015; Doyle, Carter, Shaw et al., 2012; Howard et al., 2013; Lund et al., 2013; Nilsson et al., 2011). Moreover, the lack of a relationship between severity of index offense and recidivism means that those who committed more serious offenses did not reoffend at a different rate than those who committed less serious offenses. Indeed, some studies highlight the finding that recidivism chances were greater for those with less serious index offenses than those with more serious index offenses (Bonta et al., 1998; Charette et al., 2015). In the context of risk, these findings reinforce the importance of historical factors for NCR populations to recidivate.

\section{Strengths, Limitations, and Future Directions}

The strength of this study is that it is a longitudinal design that tracked the entire Alberta NCR population throughout its history. As such, the results of this study may be generalized within Alberta and to other similar populations. A limitation was that recidivism data were available only from official CPIC records and, furthermore, coded for convictions. This suggests that our recidivism estimates were conservative, as crimes may go unreported or result in rehospitalization instead of criminal charges or convictions (Harris et al., 2015). As such, the overall limitation of our recidivism data points to the need to search for more diverse measures of outcome aside from criminal records (Charette et al., 2015). Such measures may be rehospitalization or institutional violence during time under the Review Boards for NCR populations.

This study was a part of the Alberta NCR Project, which seeks to understand those made NCR across Alberta's entire history. Other projects will involve the validation of risk assessment tools on the Alberta NCR population, predictors of desistance from recidivism, and the impact of 2014 changes to NCR legislation on Review Board decision-making.

\section{ACKNOWLEDGMENTS}

Special acknowledgements to Chayse Haldane, Troy Rieck, Alicia MacNeil, Robi Wirove, and Arielle Boyes. Jeremy Cheng was supported by a Doctoral Fellowship from the Social Sciences and Humanities Research Council of Canada.

\section{CONFLICT OF INTEREST DISCLOSURES}

The authors declare that there are no conflicts of interest.

\section{AUTHOR AFFILIATIONS}

*Department of Psychology, University of Alberta, Edmonton, AB; ${ }^{\dagger}$ Department of Psychology, University of Saskatchewan, Saskatoon, SK; ${ }^{\ddagger}$ Alberta Health Services, Edmonton, AB; ${ }^{\S}$ Department of Psychiatry, University of Alberta, Edmonton, AB, Canada.

\section{REFERENCES}

Baumer, E. P., Wright, R., Kristinsdottir, K., \& Gunnlaugsson, H. (2002) Crime, shame, and recidivism. The case of Iceland. British Journal of Criminology, 42, 40-59

Bonta, J., Blais, J., \& Wilson, H. A. (2014). A theoretically informed metaanalysis of the risk for general and violent recidivism for mentally disordered offenders. Aggression and Violent Behavior, 19, 278-287.

Bonta, J., Law, M., \& Hanson, K. (1998). The prediction of criminal and violent recidivism among mentally disordered offenders: A meta-analysis. Psychological Bulletin, 123, 123

Charette, Y., Crocker, A., Seto, M., Salem, L., Nicholls, T., \& Caulet, M. (2015). The national trajectory project of individuals found not criminally responsible on account of mental disorder in Canada: Part 4: Criminal recidivism. The Canadian Journal of Psychiatry, 60, 127-134.

Cohen, J. E. (1988). Statistical power analysis for the behavioral sciences Hillsdale, NJ: Lawrence Erlbaum Associates, Inc.

Crocker, A., Nicholls, T., Seto, M., Charette, Y., Cote, G., \& Caulet, M. (2015a). The national trajectory project of individuals found not criminally responsible on account of mental disorder in Canada. Part 2: The people behind the label. The Canadian Journal of Psychiatry, 60, 106-116.

Crocker, A., Nicholls, T., Seto, M., Cote, G., Charette, Y., \& Caulet, M. (2015b). The national trajectory project of individuals found not criminally responsible on account of mental disorder in Canada. Part 1: Context and methods. The Canadian Journal of Psychiatry, 60, 98-105.

Douglas, K. S., Guy, L. S., \& Hart, S. D. (2009). Psychosis as a risk factor for violence to others: A meta-analysis. Psychological Bulletin, 135, 679-706.

Doyle, M., Carter, S., Shaw, J., \& Dolan, M. (2012). Predicting community violence from patients discharged from acute mental health units in England. Social Psychiatry and Psychiatric Epidemiology, 47, 627-637. 
Doyle, M., Logan, C., Ludlow, A., \& Holloway, J. (2012). Milestones to recovery: Preliminary validation of a framework to promote recovery and map progress through the medium secure inpatient pathway. Criminal Behaviour and Mental Health, 22, 53-64.

Durose, M. R., Cooper, A. D., \& Snyder, H. N. (2014). Recidivism of prisoners released in 30 states in 2005: Patterns from 2005 to 2010. Washington DC: US Department of Justice, Office of Justice Programs, Bureau of Justice Statistics.

Ethgen, O., \& Standaert, B. (2012). Population- versus cohort-based modelling approaches. PharmacoEconomics, 30, 171-181.

Grann, M., Danesh, J., \& Fazel, S. (2008). The association between psychiatric diagnosis and violent re-offending in adult offenders in the community. BMC Psychiatry, 8, 92.

Haag, A. M., Cheng, J., \& Wirove, R. (2016). Describing the not criminally responsible population in Alberta's history: Sociodemographic, menta health, and criminological profiles. Journal of Community Safety and Well-Being, 1, 68-74.

Hall, D. L., Miraglia, R. P., Lee, L. W. G., Chard-Wierschem, D., \& Sawyer, D. (2012). Predictors of general and violent recidivism among SMI prisoners returning to communities in New York State. Journal of the American Academy of Psychiatry and the Law, 40, 221-231.

Hanson, R., \& Morton-Bourgon, K. (2005). The characteristics of persisten sexual offenders: A meta-analysis of recidivism studies. The Journal of Consulting and Clinical Psychology, 73, 1154-1163.

Harris, G. T., Rice, M. E., Quinsey, V. L., \& Cormier, C. A. (2015). Violent offenders: Appraising and managing risk (3rd edition.). Washington, DC: APA. Howard, R., McCarthy, L., Huband, N., \& Duggan, C. (2013). Re-offending in forensic patients released from secure care: The role of antisocial/borderline personality disorder co-morbidity, substance dependence and severe childhood conduct disorder. Criminal Behaviour and Mental Health, 23, 191-202.

IBM Corp. (2010). IBM SPSS statistics for Windows (Version 19). Armonk, NY: IBM Corp.

James, N. (2015). Offender reentry: Correctional statistics, reintegration into the community, and recidivism. Washington, DC: Congressional Research Service, Library of Congress.

Langan, P., \& Levin, D. (2002). Recidivism of prisoners released in 1994. Federal Sentencing Reporter, 15, 58-65
Luettgen, J., Chrapko, W., \& Reddon, J. (1998). Preventing violent re-offending in not criminally responsible patients. An evaluation of a continuity of treatment program. International Journal of Law and Psychiatry, 21, 89-98.

Lund, C., Hofvander, B., Forsman, A., Anckarsäter, H., \& Nilsson, T. (2013). Violent criminal recidivism in mentally disordered offenders: A follow-up study of 13-20 years through different sanctions. International Journal of Law and Psychiatry, 36, 250-257.

Marais, B., Subramaney, U. (2015). Forensic state patients at Sterkfontein Hospital: A 3-year follow-up study. South African Journal of Psychiatry, $21,86-92$.

Nilsson, T., Wallinius, M., Gustavson, C., Anckarsäter, H., \& Kerekes, N. (2011). Violent recidivism: A long-ime follow-up study of mentally disordered offenders. PloS One, 6, e25768.

O'Donnell, I., Baumer, E., \& Hughes, N. (2008). Recidivism in the Republic of Ireland. Criminology and Criminal Justice, 8, 123-146.

O'Driscoll, C., Larney, S., Indig, D., \& Basson, J. (2012). The impact of personality disorders, substance use and other mental illness on re-offending. Journal of Forensic Psychiatry \& Psychology, 23, 382-391.

Ostermann, M., \& Matejkowski, J. (2014). Exploring the intersection of mental health and release status with recidivism. Justice Quarterly, 31, 746-766.

Porporino, F. J., \& Motiuk, L. L. (1995). The prison careers of mentally disordered offenders. International Journal of Law and Psychiatry, 18, 29-44.

R. v Bouchard-Lebrun, (2011), [2011] 3 S.C.R. Available from: https://scc-csc. lexum.com/scc-csc/scc-csc/en/item/7976/index.do

Rice, M., \& Harris, T. (1992). A comparison of criminal recidivism among schizophrenic and nonschizophrenic offenders. International Journal of Law and Psychiatry, 15, 397-408

Szklo, M. (1998). Population-based cohort studies. Epidemiologic Reviews, $20,81-90$

Wang, X., Zhang, D., Jiang, S., Bai, Y., Cucolo, H., \& Perlin, M. (2007). Reassessing the aftercare treatment of individuals found not guilty due to a mental disability in Hunan, China: supplemental study into the disposition of mentally ill offenders after forensic psychiatric assessment. Australian and New Zealand Journal of Psychiatry, 41, 337-342. 